JOSÉ LUIS LACAVE

CSIC. Madrid

Hace una década el Prof. David Romano, mi buen amigo, publicó en esta misma revista un artículo de capital importancia para los estudios de la demografia judía en la Corona de Aragón y muy especialmente para la historia de la judería de Jaca '. Por ello, al sumarme gustoso al merecido Homenaje que en este volumen se le ofrece, he pensado que era muy adecuado publicar esta kétûbba de Jaca, que tiene relación con aquel artículo no sólo por tratarse de la misma ciudad aragonesa objeto primordial de su estudio, sino también por algunos detalles que luego veremos.

La kétúbbâ se conserva en el Archivo del Reino de Valencia y lleva el $\mathrm{n}^{\circ} 2$ de sus Pergaminos árabes y hebreos. Conocí su existencia, como ya expliqué en una breve nota necrológica ${ }^{2}$, gracias al infatigable deseo de ayudar de Leopoldo Piles, nuestro llorado buen amigo, tanto de David Romano como mío. Se trata de un pergamino de $46 \times 44,5 \mathrm{~cm}$. En su parte externa está escrito con letra moderna: "ARV [Archivo del Reino de Valencia]: Pergaminos árabes y hebreos n 2»; y con letra más antigua: «1569». Sirvió de tapas de un libro, de lo que le han quedado los agujeros del cosido. Está cortado en su parte inferior, tanto por el lado derecho como por el izquierdo. La kêțubbâ está bellamente decorada con una greca en el centro de la parte superior y motivos florales en el resto de la parte superior y en los laterales, todo ello en colores verdes, rojos y oros. La letra cuadrada es de desigual tamaño, mientras la cursiva es la española habitual. En general buen estado de conservación, en algunas letras y algunas palabras se ha perdido la tinta, haciéndolas ilegibles.

- Este artículo se terminó de redactar el 30 de abril de 1991.

1 D. Romano, "Prorrata de contribuyentes judíos de Jaca en 1377 », Sefarad XLII (1982) 3-39.

2 Sefarad L (1990) pág. 129. 
Se trata de la kẹtûbbâ del matrimonio de Yôsef bar Šem Tôb Așig con Oro, hija de Yôsef Guyos celebrado en Jaca el 9 de sébat del año 5189 (14 de enero de 1429). Lleva la firma, además de la del novio, de hasta siete testigos, aunque sólo en dos de ellos aparece la palabra "ed".

En la cabecera lleva un preámbulo en que se recogen dos versículos bíblicos; uno de ellos (Sal 128,3), alusivo a la felicidad de la vida matrimonial, con elogio de esposa e hijos, y el segundo (Gen 49,22), alusivo al nombre del novio, Yôsef. Luego comienza la $k e \underline{t} u \hat{b} b b \hat{a}$ propiamente dicha, en letra cuadrada. Tras la fecha, lugar y nombres de los novios, vienen las cláusulas habituales: 1) fórmula matrimonial y môhar; 2) tósefet ('adición'); 3) Nědûnya' ('dote'); y 4) garantía por parte del novio de kétubbâ, tósefet y nědûnya'. Se termina la letra cuadrada con las fórmulas habituales de conclusión y las firmas, lógicamente en letra cursiva, del novio y los siete testigos.

Al pie de la letra cuadrada, y ya en letra cursiva, se recoge la mattane lěhud que el novio da a la novia y que consiste en una casa de su propiedad sita en Jaca, "en el barrio de los judíos", "contigua al adarve", la muralla. La casa, de la que se dan sus lindes, la había recibido el novio de su madre un año antes de la boda por una escritura de donación - que se cita aquí- fechada en Jaca el último día del mes de tebet del año 5188 (17 de enero de 1428).

El estudio de David Romano se basaba en una lista nominal de 115 contribuyentes judíos de Jaca en 1377. Ahora nos interesa resaltar que en ella aparecen con profusión los siguientes "apellidos": Almosnin, 12 veces; Abengoyos, Avingoyos, Avenguyos o Avinguyos, 8 veces; Alnieto, Elnieto o lo Nieto, 4 veces; Empapur, 3 veces. Además aparece una vez Pinfas, si no es lo mismo que Ampifas, Ampifaz, Empifas, como sospecho, en cuyo caso habría que sumarle 5 veces más.

Veamos ahora los nombres que aparecen en nuestra kẹtûbba: el novio, Yôsef bar Šem Tôb Aşig ${ }^{3}$; la novia, Oro, y el padre de ésta, Yôsef Guyos; los testigos, Abraham bar Yôsef ben Papur, Złrahyâ bar Ya`aqob ben Almosnino, Mošeh bar Keșem ${ }^{4}$, Yôsef Almosnino,

\footnotetext{
${ }^{3}$ No se qué grafia llevaría este "apellido" en romance; la sade es letra que rara vez se usa en las versiones romanceadas. En todo caso no se parece a ninguno de los "apellidos" de 1377.

${ }^{4}$ Lectura dudosa; tampoco se parece a ninguno de 1377.
} 
Šem Tôb bar Yiş̧aq Guyos, Yişhaq bar Abraham Ajaf o Akaf s y Yěhûdâ bar Abraham Almosnino; propietarios de casas que lindan con la que es objeto de mattanâ, Yôsef Alnieto y Šělomoh bar Šřmû'el Pinhas; testigos de la donación de dicha casa, Yôsef bar Yěhûdâ Almosnino, que pudiera ser el mismo que el Yôsef Almosnino testigo de la kẹtubbbâ, y Yôsef bar El‘azar Alnieto, que pudiera ser el mismo Yôsef Alnieto vecino del novio; el hermano del novio, Abraham [bar Šem Tôb Așig]; y la madre del novio, Orabuena. En total 11 ó 13 varones y dos mujeres.

Como vemos, entre los personajes de la kețûbbâ, que es de 1429 , hay 3 ó 4 Almosnino o Almosnin, 2 Guyos o Abengoyos, 1 ben Papur o Empaur y uno o dos Alnieto, coincidentes con "apellidos" que salen con profusión en la lista de 1377. Además, aparece un Šlomoh Pinhas, que sospecho que sea lo mismo que S. Pinfas o Ampifas.

Esto supone que medio siglo después de 1377 los "apellidos" corrientes entre los judíos de Jaca eran los mismos. Pero en medio habian ocurrido los nefastos sucesos de 1391 y las subsiguientes conversiones con la secuela conocida en Aragón de la dispersión de los judíos por muchos pueblos y aldeas. Sin embargo, hemos de pensar que en Jaca se mantuvo en lo esencial el mismo núcleo de familias.

Por otro lado, el hecho de que la kétubbd se haya conservado en un archivo valenciano y que el "apellido" del novio sea tan "extraño" -en una kettubba valenciana que se publicó hace unos años 6 , los nombres del novio y algunos testigos son también bastante "extraños" - me hacen pensar que el tal novio quizá perteneciera a una familia valenciana, de Valencia o de alguna población del reino como Játiva, Sagunto, etc., emigrada en el siglo XV a Jaca - no llevaría allí muchos años cuando tuvo lugar esta boda, 1429- y que años después de la boda, dicho novio con su esposa y demás familia emigraron de nuevo a alguna localidad levantina, aunque desde luego no a Valencia, donde ya no había comunidad judía en el siglo Xv. Claro que el hecho de que la ketrubba estuviera en Valencia puede deberse a múltiples motivos. De todos modos, me parece que

\footnotetext{
${ }^{5}$ Lectura dudosa; no se parece a ninguno de 1377.

6 V. Collado Bertomeu y R. Robres Lluch, "Textos hebreoaramaicos en el archivo de la Catedral de Valencia", Primer Congreso de Historia del Pats Valenciano, vol. I, Valencia 1973, págs. 341-346.
} 
lo interesante de esta reflexión es lo relacionado únicamente con Jaca.

\section{EDICIÓN DE LA KĚT̃ÔBBẦ}

אשתך כגפ פריה בירכתי ביתך בניך משתלי זיתים סביב לשלחקך ?. מ פרת ווסף.

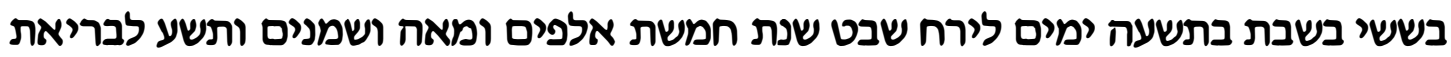

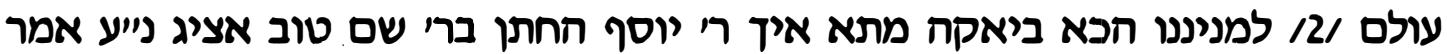

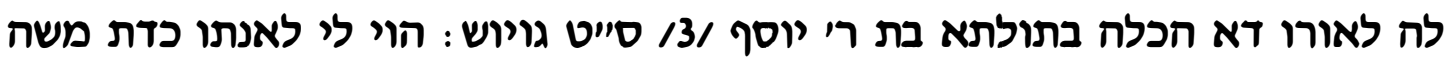

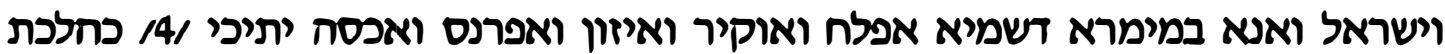

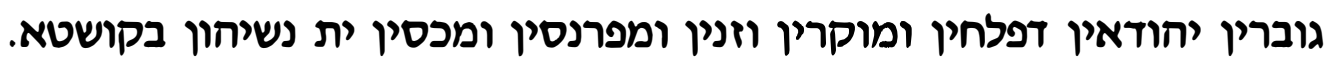

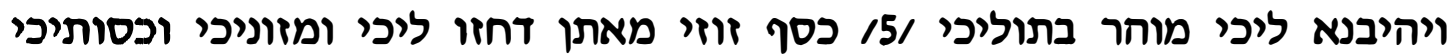

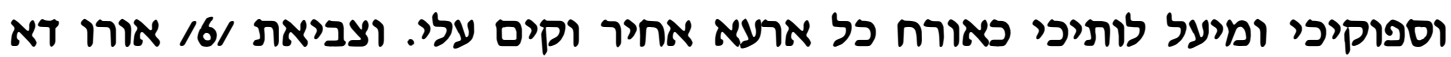

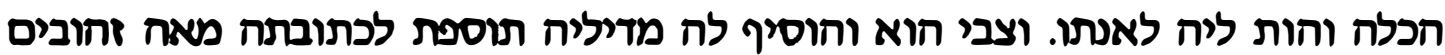

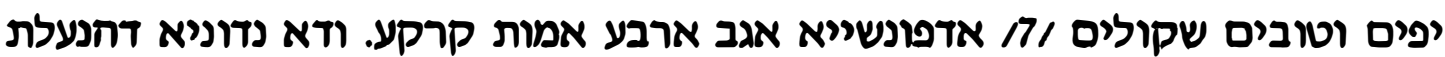

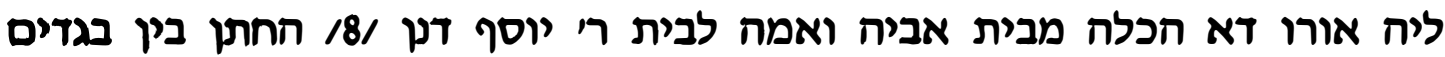

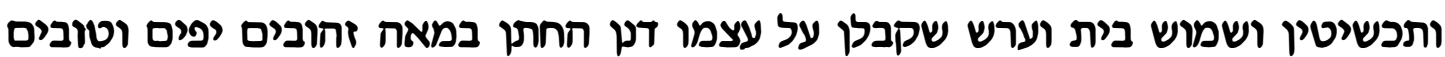

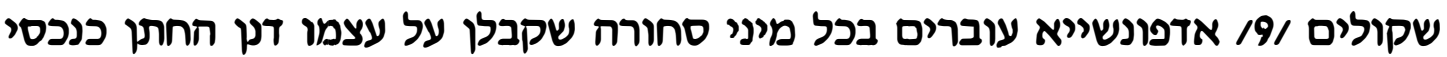

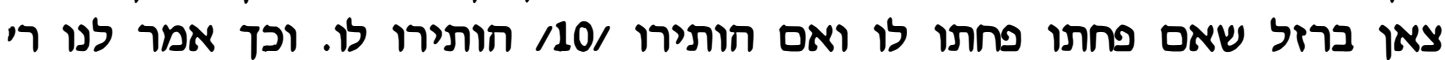

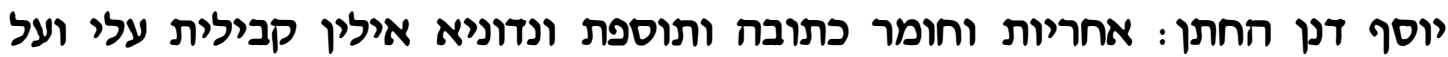

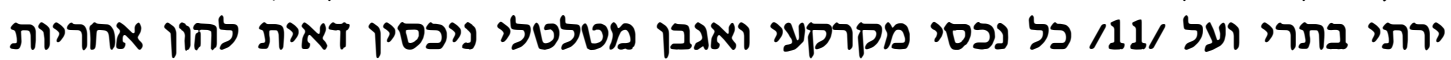

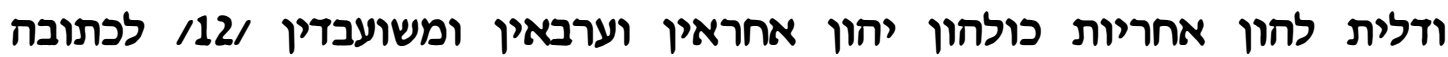

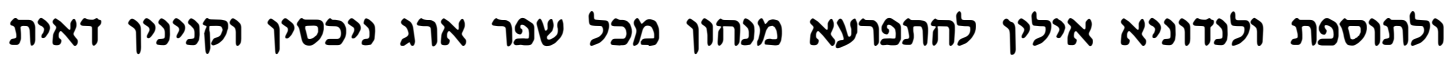

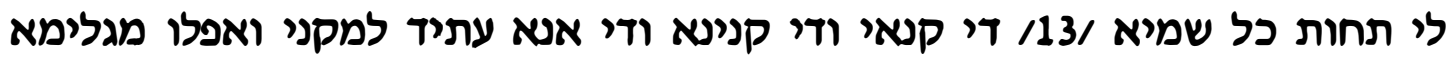

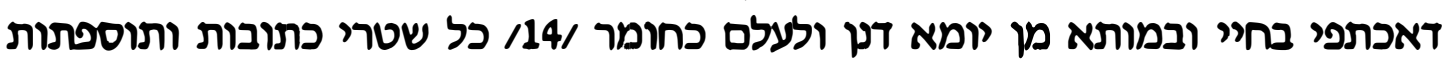

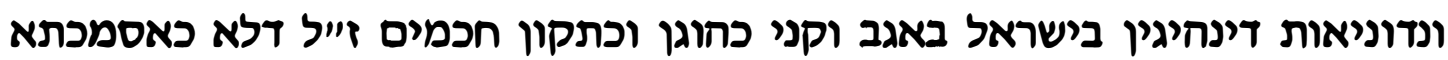

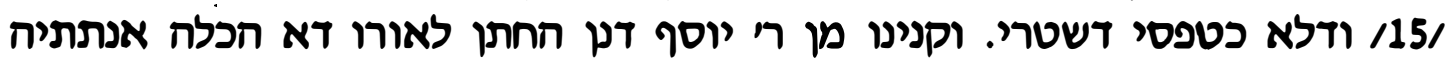

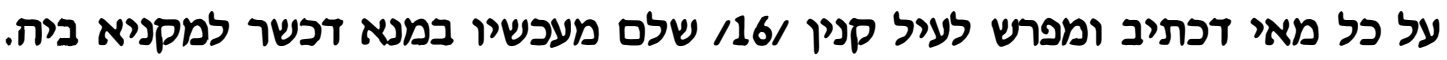

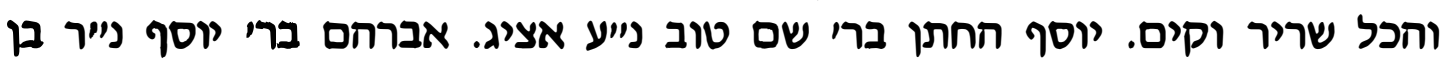

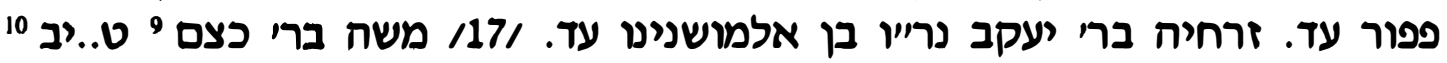

\footnotetext{
7 Sal 128,3.

8 Gen 49,22. El novio se llama יוסף.

9 También pudiera leerse

10 Ilegibles las letras que faltan. 


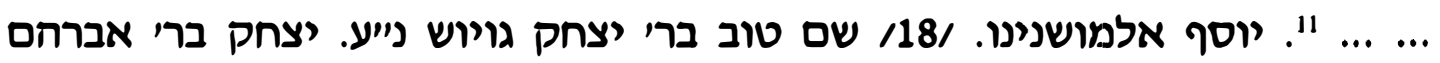
אכף 12 נ"ע נ"ע. /19/ יהודה ברי אברחם נר"ו בן אלמושנינו.

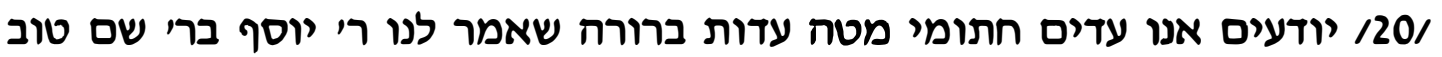

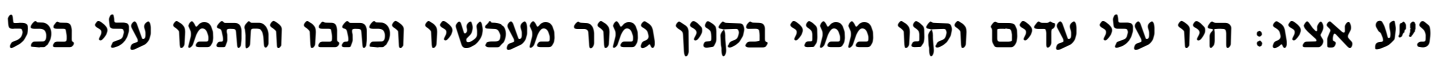

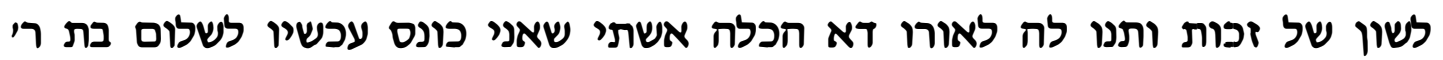

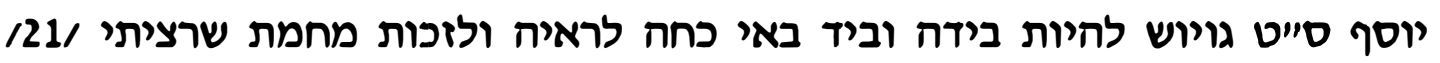

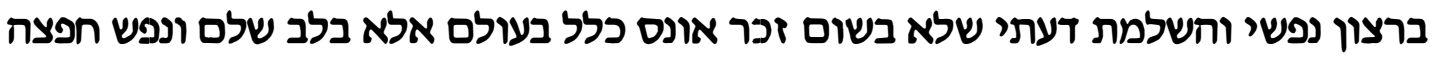

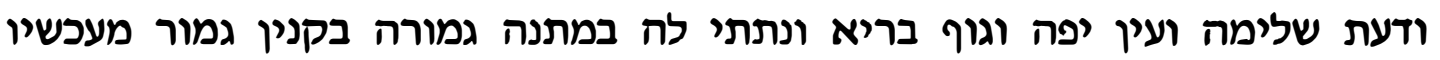

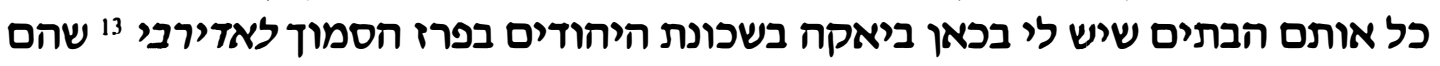

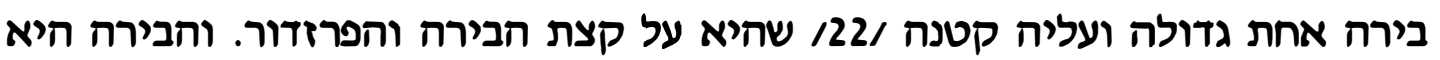

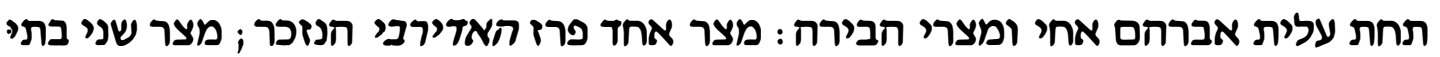

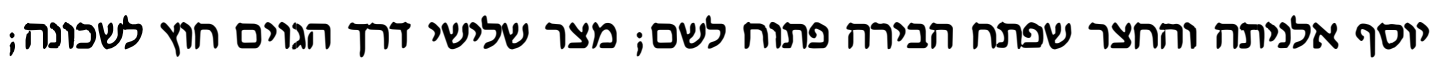

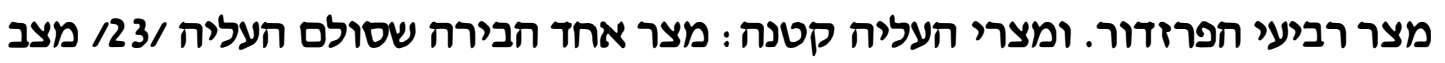

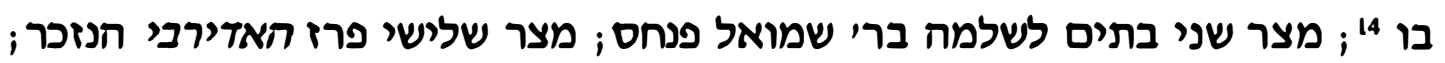

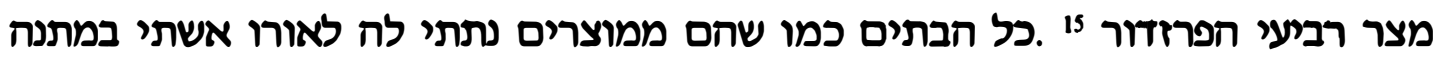

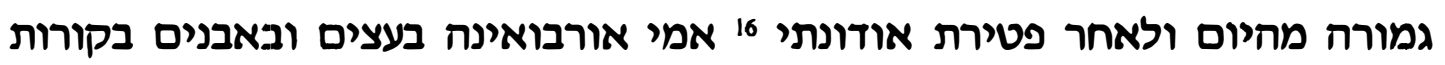

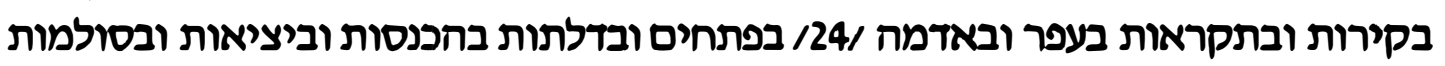

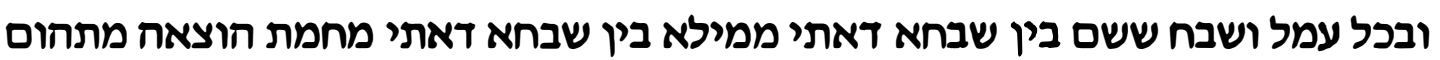

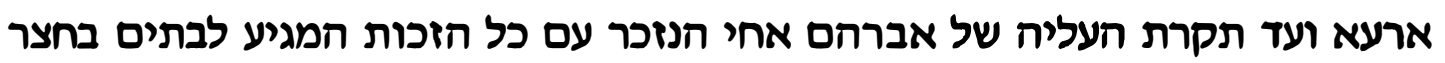

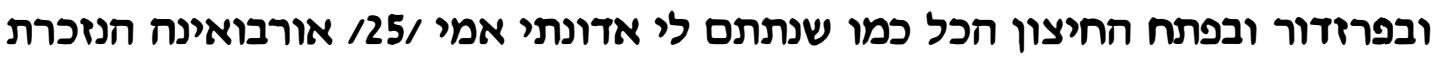

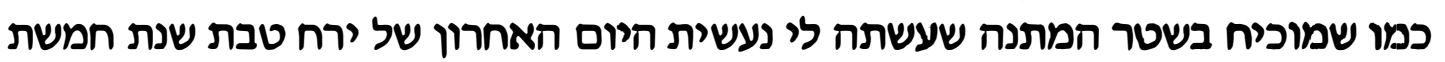

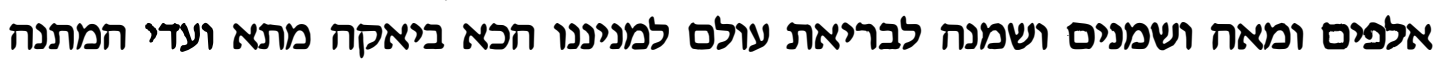

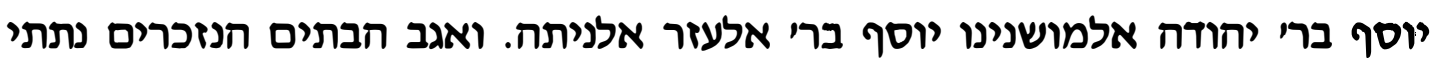

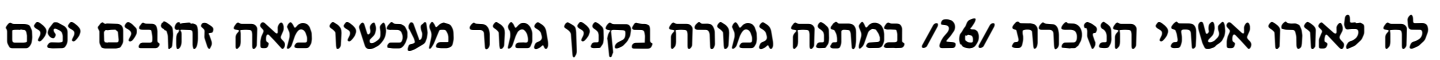

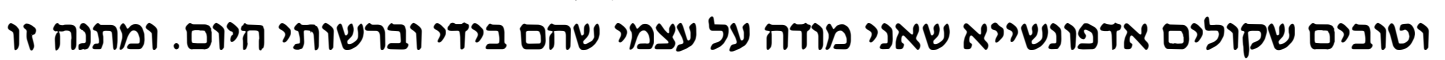

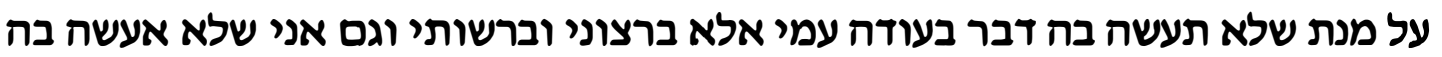

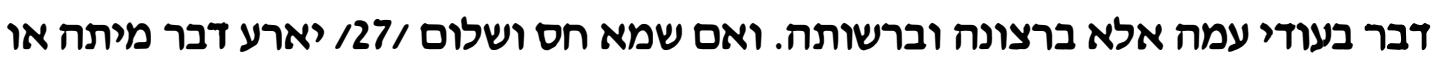

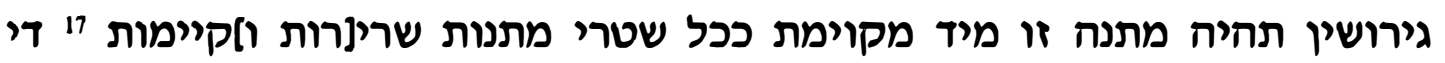

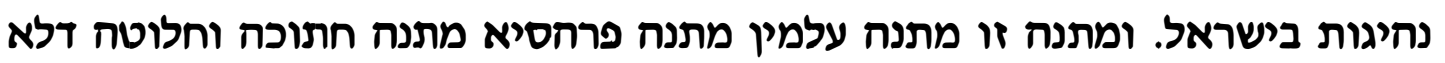

\footnotetext{
1 Dos palabras ilegibles.

12 También pudiera leerse אנק o אכק , אנר.

13 Aderbe, adarve, muralla.

14 Sic. Probablemente, el escribano tenía en mente la palabra aragonesa "palacio», más que la hebrea "בירה".

15 Encima de esa palabra, pone: אויר.

${ }^{16} \mathrm{El}$ amanuense empezó a escribir (אור)(בואינח) y luego quiso corregir para poner אדונתי; corrigió el 7 en 7 (y se nota la corrección), pero se olvidó del i que va detrás del א.

17 Las letras que van entre corchetes, ilegibles.
} 
למיהדר בה חלא לחשטטה מינה לעלם מנוקה ומשופה מכל מיני [ערעוזרין ומיו שבעולם.

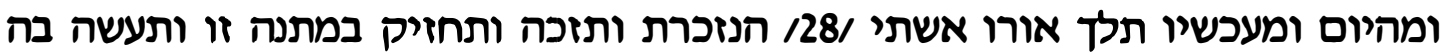

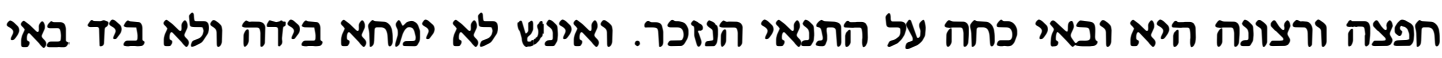

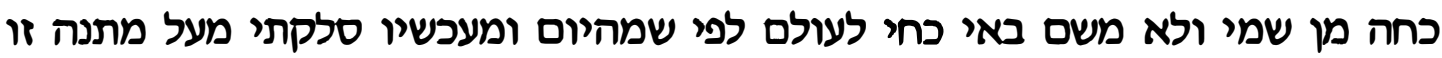

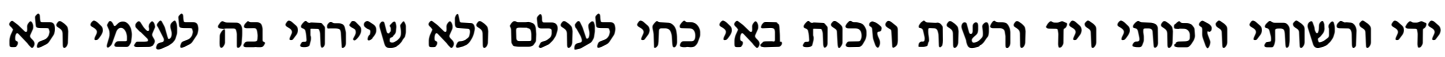

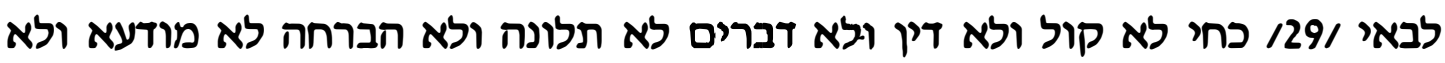

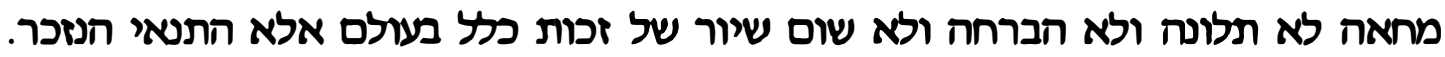

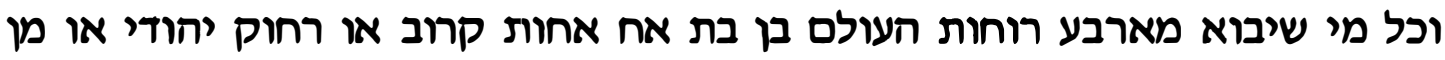

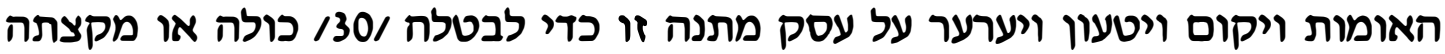

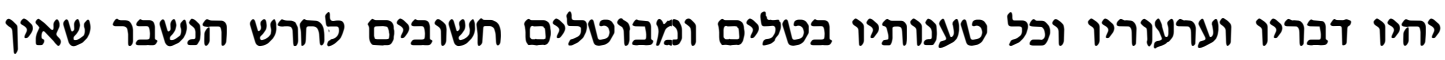

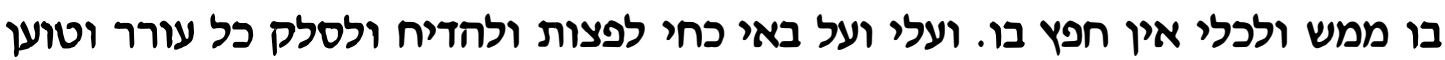

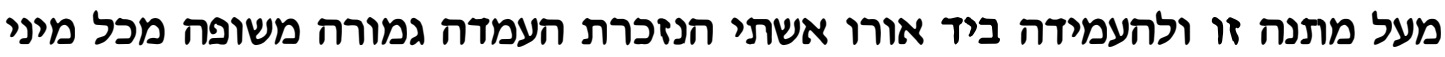

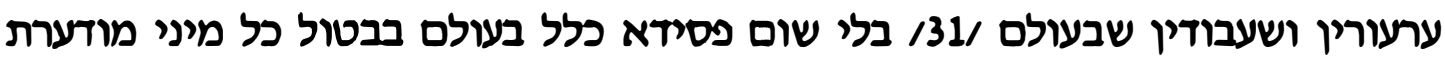

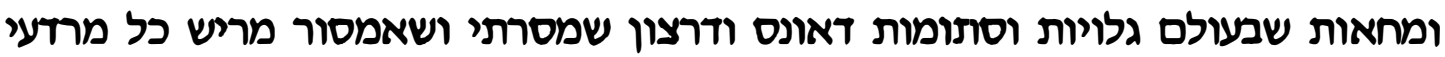

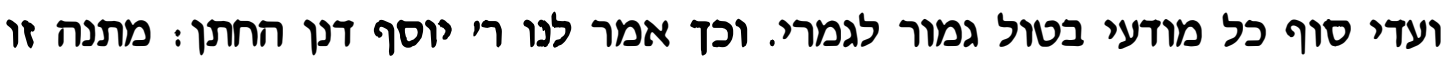

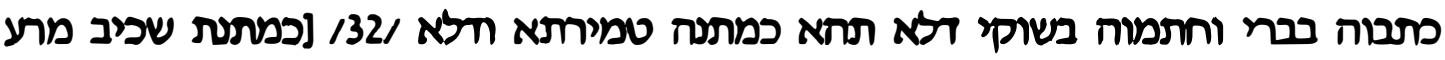

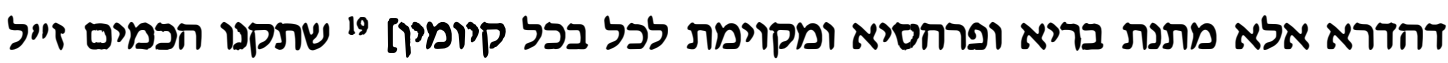

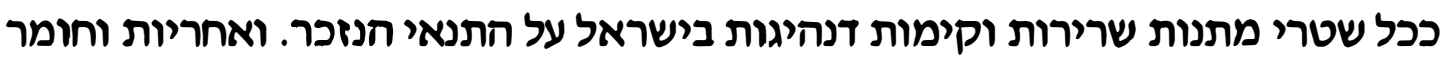

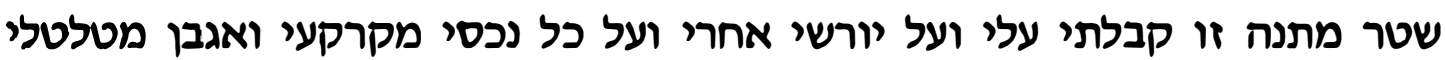

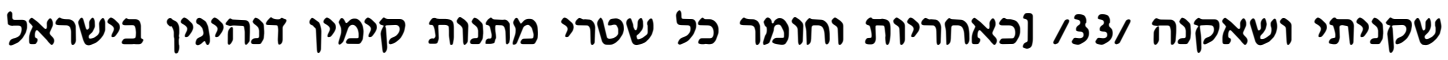

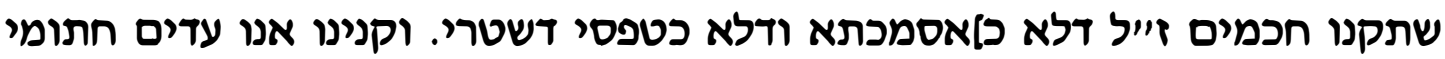

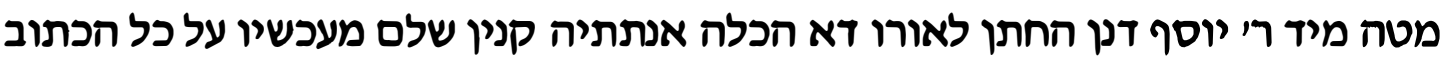

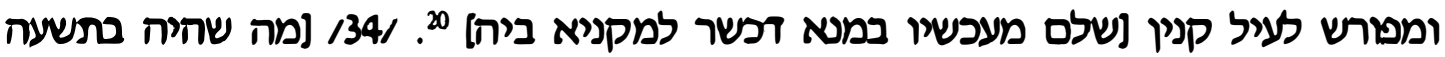

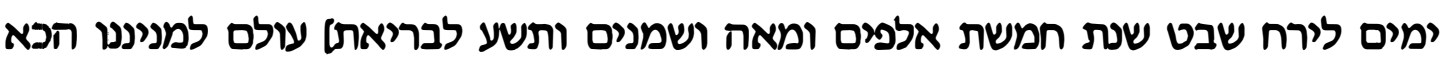

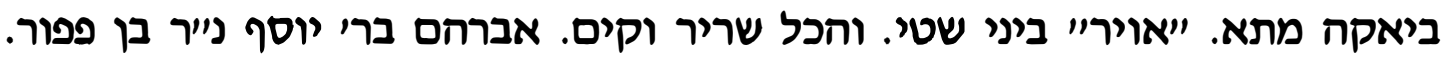
זרחיח ברי יעקב נר"ו בן אלמושנינו. ביני שני וחל

VERSIÓN ESPAÑOLA

(Traducimos sólo el fragmento interesante de la mattana lěḩud. El texto de la kétubbâ es el habitual ya conocido de los lectores de Sefarad por un artículo de F. Cantera publicado en estas mismas

18 Un pequeño agujero impide leer las letras que van entre corchetes.

19 El pergamino está cortado en su parte inferior tanto por el lado derecho como por el izquierdo. A partir de aquí y hasta el final falta el comienzo de todas las líneas (tres), aproximadamente doce palabras en cada una. La reconstrucción la hacemos a base de otras kétubbott espanolas.

20 Por la razón expresada en la nota anterior, falta el final de esta línea, unas seis palabras. 
páginas ${ }^{21}$. Y lo que sigue a lo traducido son las fórmulas de derecho rabínico habituales en una escritura de donación).

Sabemos nosotros, los testigos abajo firmantes, con testimonio claro, que nos dijo R. Yôsef bar Šem Tôb, su alma descanse en el Edén, Așig: Sedme testigos y tomad quinyán de mí, con quinyán íntegro desde ahora, y escribidme y firmadme con todo lenguaje de derecho, y dádselo a Oro, esta novia, mi esposa que yo desposo ahora en paz, hija de R. Yôsef, su fin sea para bien, Guyos, para que sirva en su mano y en mano de sus representantes de prueba y de constatación de derecho, porque quiero voluntariamente y con plena consciencia, sin ningún género de coacción en absoluto, sino de todo corazón, voluntariamente y con plena consciencia, de buen grado y en perfecto estado de salud, darle con donación íntegra, con quinyán íntegro desde ahora, todas las casas que tengo aquí en Jaca, en el barrio de los judíos, en la zona contigua al aderbe ${ }^{22}$ que consisten en un palacio ${ }^{23}$ grande y una buhardilla pequeña, la cual está sobre el palacio y el corredor. El palacio está debajo de la buhardilla de mi hermano Abraham y los lindes del palacio son: uno, la mencionada zona del aderbe; linde segundo, casa de Yôsef Alnieto y el patio donde se abre la puerta del palacio; linde tercero, la calle de los cristianos, fuera del barrio; linde cuarto, el corredor. Y los lindes de la buhardilla pequeña son: uno, el palacio donde está colocada la escalera de la buhardilla; linde segundo, casa de Šlomoh bar Šmú’el Pinhas; linde tercero, la mencionada zona del aderbe; linde cuarto, el corredor.

Todas las casas tal como están delimitadas se las doy a Oro, mi esposa, con donación íntegra desde hoy y después de la muerte de mi señora madre Orabuena, con maderas y piedras, vigas, paredes y techos, tierra y suelo, aberturas y puertas, entradas y salidas, y escaleras, y con toda obra y mejora que haya en ellas, tanto una mejora que llegue por sí misma como una mejora que llegue mediante gasto, desde lo profundo de la tierra hasta el techo de la buhardilla de mi citado hermano Abraham, con todos los derechos que le sobrevienen a las casas en el patio y en el corredor y en la puerta exterior. Todo tal como me las dio a mí mi señora madre, la citada Orabuena, según se muestra en la escritura de la donación que me hizo, la cual fue hecha el último día del mes de tebet del año 5188 (17 de enero de 1428) de la Creación según nuestro cómputo, aquí, en la ciudad de Jaca, siendo testigos de la donación Yôsef bar Yěhuda Almosnino y Yôsef bar El'azar Alnieto. Y además de las casas mencionadas le doy a Oro, mi

${ }^{21}$ "La "ketuba" de D. Davidovitch y las ketubbot españolas", Sefarad XXXIII (1973) 375-386.

22 En romance en el texto hebreo; adarve, muralla.

${ }^{23}$ Palacio en aragonés era equivalente a casa. 
citada esposa, con donación íntegra, con quiyán íntegro desde ahora, cien monedas de oro y de buen peso, alfonsíes, que yo reconozco que están en mi mano y en mi poder hoy día.

Y esta donación es con la condición de que no hará nada con ella mientras esté conmigo, si no es contando con mi consentimiento y con mi autorización, y de que tampoco yo haré nada con ella mientras esté con ella si no es contando con su consentimiento y su autorización.

Y si, Dios no lo quiera, ocurriera cosa de muerte o de divorcio, sea esta donación inmediatamente sancionada como todas las escrituras de donación firmes y permanentes acostumbradas en Israel.

Y esta donación es una donación perpetua, donación pública, etc., etc.

\section{RESUMEN}

Hace unos años David Romano publicaba una lista nominal de 115 contribuyentes judíos de Jaca en 1377. El autor edita ahora una kétubbd de Jaca de 1429, que, en cierto modo, le sirve de complemento. Separados ambos documentos por el crucial año 1391, se observa, sin embargo, que en la ciudad aragonesa se mantuvo en el siglo XV el mismo núcleo de familias del siglo XIV.

\section{SUMMARY}

Some years ago, David Romano published a nominal list of 115 Jewish taxpayers of Jaca in 1377. In this article the author edits a ketubba from Jaca dated in 1429 that, in a certain way, serves as a complement. Although separated by the crucial year of 1391, both documents show evidence that, the same nucleus of families coming from the 14th century was maintained in that Aragonese town in the 15 th century. 